\title{
Consideraçōes sobre os processos de sedimentação na água preta ácida do rio Negro (Amazônia Central)
}

\author{
Jerry A. Leenheer $\left({ }^{*}\right)$ \\ Umberto de Menezes Santos (**)
}

\section{Resumo}

A morfologia alongada e estreitada das ilhas fluviais chamadas de arquipélago das Anavilhanas, encontrado no baixo rio Negro, sugerem processos de sedimentação que diferem de outros tributários do Amazonas, que têm ilhas fluviais na forma de lentes. Um estudo da geoquímica da água e sedimento do rio $\mathrm{Ne}$ gro, rio Branco e rio Solimões sugere que sedimentos caoliníticos em suspensão do rio Branco estavam sendo floculados pela água preta ácida do rio Negro, face à redução do $\mathrm{pH}$ ao ponto zero de carga do sedimento, e à formação de complexos argiloso caulin-húmico. Nenhuma floculaçăo de sedimento foi observada onde o rio Negro se combina com o rio Solimōes, uma vez que a mudança de $\mathrm{pH}$ nesta convergência era pequena. A sedimentação de floculados no baixo rio Negro produz depósitos năo estratificados, os quais são manifestados por ilhas alongadas consistindo principalmente de silte e argila, e sedimento do leito do conteúdo muito alto de argila.

\section{INTRODUÇÃO}

Os processos de sedimentação que formam ilhas fluviais nos principais tributários do rio Amazonas foram de modo geral descritos por Sioli (1966). A maioria dos tributários do Amazonas formam lagos fluviais perto de suas bocas, como uma conseqüência da elevação Holocena do nível do mar. Ilhas fluviais formam-se tipicamente próximo à cabeceira destes lagos fluviais, porque o sedimento em suspensão é depositado quando a velocidade da corrente do tributário diminui.

O rio Negro também tem um lago fluvial e uma zona de sedimentação que é parcialmen. te cheia de ilhas fluviais, coletivamente chamadas de arquipélago das Anavilhanas; contudo, a forma alongada destas ilhas (Fig. 1) é diferente das ilhas fluviais em forma de lentes na maioria dos outros tributários do Amazonas. Em sua boca, o rio Negro contém baixas quantidades de sedimento em suspensão, em concentrações próximas de $5 \mathrm{mg} / \mathrm{L}$ (Meade et al., 1979) embora o rio Branco deposite concentrações moderadas de sedimento em suspensão (estimado como variando entre 50 e $300 \mathrm{mg} / \mathrm{L}$ ) no rio Negro, cerca de 300 quilômetros acima de sua boca. Em geral, cursos d'água e rios de água preta da região amazônica foram observados como sendo muito pobres em sedimentos em suspensão, o que faz supor estar relacionado com a alta acidez da água preta (João Ores des Schneider, comum. pessoal, 1978). Tanto a distinta forma das ilhas fluviais das Anavilhanas como as baixas concentrações de sedimentos em suspensão nas águas do rio Negro sugerem um processo de sedimentação invulgar no rio Negro.

Duas características invulgares da água preta do rio Negro comparadas com os tributários de "água branca" e "água clara" do Ama. zcnas, são de alto conteúdo orgânico solúvel e de alta acidez. Para investigar os efeitos que solutos orgânicos e pH podem ter sobre os processos de sedimentação no rio Negro, uma excursão de observação e coleta no rio Negro de Manaus até a boca do rio Branco (Fig. 1) foi feita de $31 / 03$ a $09 / 04 / 1978$, no barco "Pyatã", do Instituto Nacional de Pesquisas da Amazônia (INPA). Presumimos que o alto conteúdo orgânico solúvel e baixo $\mathrm{pH}$ do rio Negro floculou os sedimentos finos em suspensão adicionados pelo rio Branco para dar as invulgares formas de ilha do arquipélago das Anavilhanas. O objetivo deste trabalho é apresentar dados e critérios de observação sobre a floculação de sedimentação que poderiam estar ocorrendo na água preta ácido do rio Negro.

(*) - United States Department of the Interior Geological Survey - Estados Unidos.

("*) - Instituto Nacional de Pesquisas da Amazônia, 


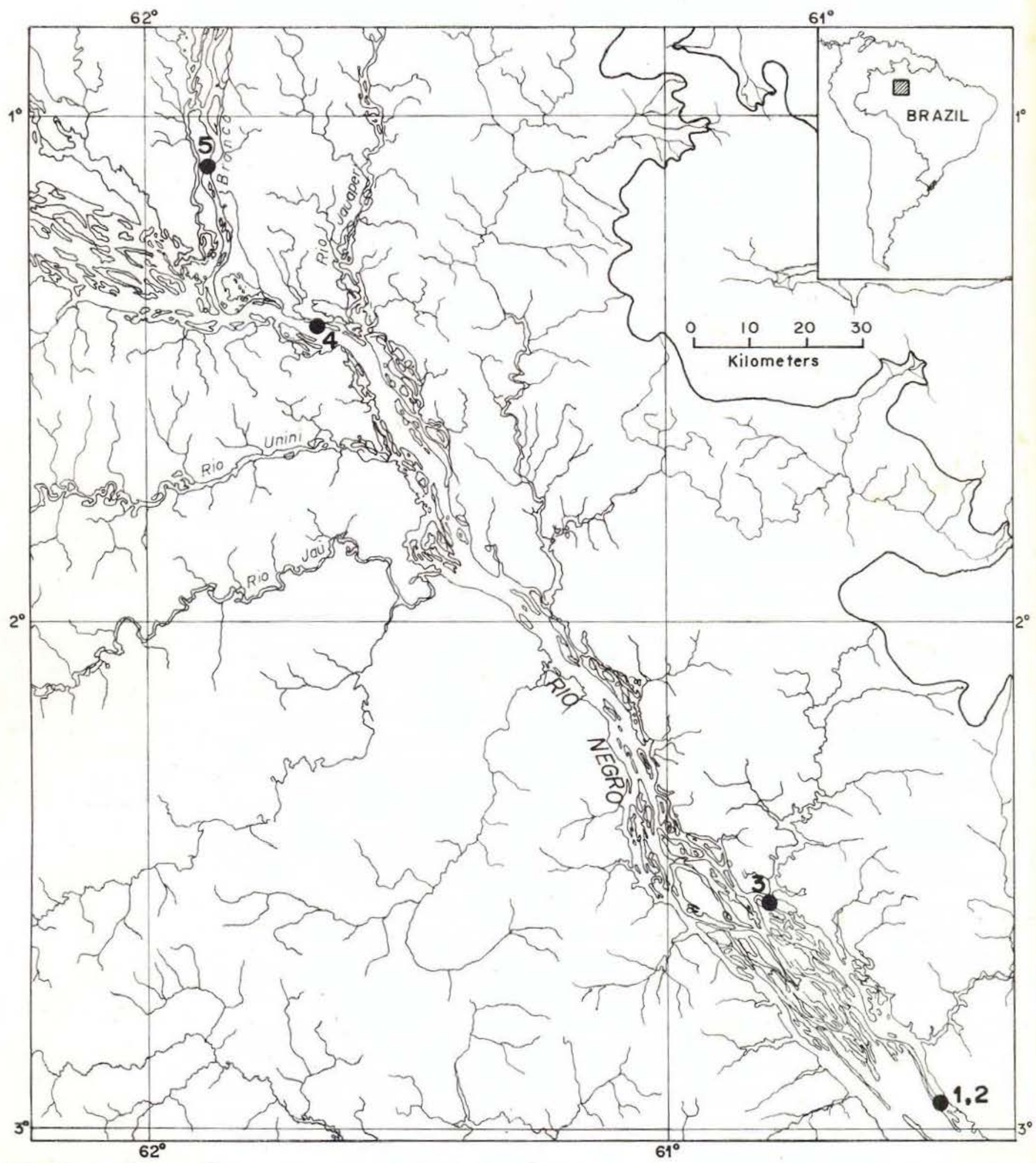

Fig. 1 - Mapa do rio Negro entre o rio Branco e Manaus, mostrando o arquipélago das Anavilhanas. Número referentes aos locais de coleta e sedimento descrito no texto.

\section{MATERIAIS E MÉTODOS}

PROCEDIMENTOS DE COLETAS E LOCAIS DE COLETA

Equipamento de coleta especializado projetado para coletar sedimento do leito não era disponivel. Sedimento depositado recentemen. te foi coletado à mão com garrafas de vidro de um litro de boca grande nas pontas posteriores das ilhas fluviais. As amostras de sedi mento foram coletadas nos seguintes locais : 
(1) Amostra 1 (designada baixas Anavilhanas) foi coletada na ilha Grande perto do lago Comprido; (2) Amostra 2 (designada sedimento do leito do rio Negro) foi obtida no lago Comprido, aproveitando-se o sedimento do leito das patas da âncora do barco; (3) Amostra 3 (de signada médias Anavilhanas) foi obtida de uma ilha oposta à boca do rio Apuaú; (4) Amostra 4 (designada rio Negro abaixo do rio Branco) foi coletadá próximo do Paraná de Floresta cerca de $20 \mathrm{~km}$ abaixo da boca do rio Branco; (5) Amostra 5 (designada rio Branco) foi coletado de uma ilha do rio Branco cerca de $30 \mathrm{~km}$ acima de sua boca.

Amostras de água para análise orgânico foram coletadas em uma garrafa de vidro de um litro; amostras de água para análise inorgânica foram coletadas em garrafas de polietileno de um litro lavadas com ácido. Todas as amostras de água eram amostras de mergulho coletados perto da superfície. Amostras de água para análise orgânica eram filtradas à pressão no local através de um filtro de membrana de prata com porosidade de $0,45 \mu \mathrm{m}$ (Malcolm \& Leenheer, 1973), e eram guardadas em caixotes providos de esponja para evitar a quebra das garrafas de vidro. Amostras de água de grande volume necessárias para experimentos de mistura de rio foram coletadas em garrafas de polietileno de 5 litros.

Amostras de água foram coletadas nos seguintes locais: (1) rio Solimões logo acima da baca do rio Negro; (2) rio Negro no estreito; (3) rio Negro logo acima do rio Branco; (4) rio Branco cerca de $30 \mathrm{~km}$ acima de sua desembocadura no rio Negro.

\section{PROCEDIMENTOS DE LABORATÓRIO}

Análise de tamanho de partícula das amostras de sedimentos foi determinada pelo método peneira-pipeta (Guy, 1969). Matéria orgânica foi destruída com peróxido de hidrogênio, e as amostras foram separadas com hexametafosfato de sódio antes que as análises de tamanho de partículas fossem efetuadas.

Carbono orgânico foi determinado no sedimento do leito por um procedimento de Van Slyke modificado (Malcolm et al., 1973). Matéria orgânica foi isolada do sedimento do leito por uma extração de $24 \mathrm{~h}$ com $\mathrm{NaOH} \mathrm{0,05}$ $\mathrm{N}$ sob nitrogênio, filtração do extrato através de um filtro de membrana de porosidade 0,45 $\mu \mathrm{m}$, remoção do $\mathrm{NaOH}$ do extrato processandoo através de resina trocadora de cation Bio Rad Ag-MP-50 de hidrogênio saturado e secando por congelamento o extrato de matéria orgâ nica.

Matéria orgânica dissolvida na água do ric Negro foi isolada por secagem por congelação de toda a amostra de água. Composição e concentração de solúvel orgânico foi determinada por análise de fracionamento de carbono orgânico dissolvido (Leenheer \& Huffman, 1979), efetuada por Huffman Laboratories, Wheat Ridge, Colorado.

Matérias orgânicas isoladas foram caracterizadas por análise infra-vermelha efetuada em um espectofotômetro infravermelho Perkin Elmer Model 580 usando-se um micro pellet $\mathrm{KBr}$. Análise de elementos $(\mathrm{C}, \mathrm{H}, \mathrm{O}, \mathrm{N}$, e cinza) de matéria orgânica isolada foi determinada pelos Huffman Laboratories. Constituintes inorgânicos das amostras de água foram analisadas por Robert Stallard do Massachusetts Institute of Tecgnology. Condutividade e pH foram medidos no INPA imediatamente após a excursão de coleta de amostra no rio Negro

Amostras d'água completas do rio Negro no estreito e rio Solimões logo acima do rio Negro acima do rio Branco, e do rio Branco logo acima de sua boca foram combinadas em várias proporções em frascos Erylenmeyer de $250 \mathrm{ml}$. pH e condutividade foram medidos após 24 horas de equilíbrio. Excesso de $\mathrm{CO}_{2}$ dissolvido foi retirado por forte agitação antes das medidas de $\mathrm{pH}$ e condutividade.

\section{Resultados E Discussão}

\section{OBSERVAÇÕES DE CAMPO}

As ilhas de argila do arquipélago das Anavilhanas são obviamente formadas pela deposição de sedimento lançados do rio Branco; as ilhas de argila, que estão distribuídas através do rio no baixo arquipélago das Anavilhanas, tornam-se progressivamente localizadas nos lados leste e norte do rio Negro quando a aproximação é feita pelo baixo rio da boca do rio Branco, que entra na margem norte do rio $\mathrm{Ne}$ gro (Fig. 1). As margens oeste e sul do rio 
Negro na distância de Manaus até o rio Branco são grandemente constituídas de areia branca, característica dos solos podzol da região. Acima da boca do rio Branco, existem umas poucas ilhas no rio Negro surgindo da deposição de sedimentos do rio Demini, porém a maioria das ilhas no rio Negro acima do rio Branco são compostas de areia e rochas.

Várias características distintivas das ilhas de argila no rio Negro são:

1. A cabeça e lados destas ilhas freqüentemente exibem margens verticais e escavações indicativas de processos erosivos, contudo durante o período da excursão no qual o rio estava enchendo e tinha submergido algumas das ilhas mais baixas, nenhuma erosão ativa estava ocorrendo. As margens de argila verticais eram extremamente estáveis mesmo onde o rio tinha velocidades moderadas de corrente;

2. Não existem bancos de areia na região de ilhas de argila do rio Negro como existem no rio Branco. Os canais entre as ilhas de argila são bem definidos, e o risco de encalhar o barco em um banco de areia é inexistente. Depósitos extensivos de areia ocorrem no rio Negro em sua margem sudoeste por toda a extensão do arquipélago das Anavilhanas, e em ambas as margens acima e abaixo desse arquipélago;

3. As margens verticais erodidas das ilhas de argila não mostram evidências de estratificação causada por seleção de tamanho de partícula durante a deposição sazonal de sedimentos. Depósitos aluviais erodidas de sedimentos ao longo de ambos os rios, Branco e Amazonas são bem estratificados.

A única extensão do rio Negro onde sedimento em suspensão era óbvia foi numa extensão de $30 \mathrm{~km}$ entre as bocas do rio Jauaperi e rio Branco. Parecia que sedimentos muito finos do rio Branco, que têm uma aparência branco-esverdeada, estava sendo floculado em partículas de tamanhos maiores; partículas separadas podiam ser vistas em suspensão no rio Negro, mas não no rio Branco. Sedimento em suspensão misturado com a água preta do rio Negro dava uma cor marrom à água; esta água marrom era restrita principalmente em um canal entre uma ilha de argila alongada e a margem norte do rio Negro.

\section{ANÁLISE DA ÁGUA}

As análises dos solutos inorgânicos das amostras de água do rio Negro, rio Solimões e rio Branco coletadas durante a excursão são dadas na tabela 1, e análises dos solutos orgâ. nicos, conforme caracterizada pela análise de fracionamento de DOC, são dadas na tabela 2.

A tabela 1 mostra as concentraçöes extremamente baixas de soluto inorgânico que ocorrem na água preta do rió Negro. O rio Branco também tem baixas concentrações e somente o rio Solimões contém moderadas concentra. ções de solutos inorgânicos dissolvidos. As concentrações de soluto orgânico (Tabela 2) são alta no rio Negro, moderada no rio Soli. mões e baixa no rio Branco.

Para estimar-se a importância relativa de solutos orgânicos versus solutos inorgânicos em determiar parâmetros dependentes de ion de $\mathrm{pH}$ e condutividade específica, uma análise iônica foi computada para dados apresentados nas tabelas 1 e 2 . Os resultados são apresensentados na tabela 3 . Miliequivalentes catiônicos incluiam todos os metais na tabela 1 mais ion hidrogênio do $\mathrm{pH}$.

Miliequivalentes aniônicos incluiam ânions inorgânicos excetơ sílica, e ânions ácido orgânico. A sílica não foi incluída porque ela existe principalmente na forma não iônica do $\mathrm{pH}$ das amostras. Os miliequivalentes ácido-orgânicos foram computados pela adição do carbono or. gânico dissolvido das frações ácido-hidrofóbicas e ácido-hidrofílicas da tabela 2, multiplicando-se o resultado por 0,0129 . O fator 0,0129 dá miliequivalentes por unidade de carbono dissolvido; este fator foi determinado por titulação de frações ácidas de uma amostra de água preta. Para águas cujo $\mathrm{pH}$ é perto da neutralidade e acima, a maioria dos grupos fracamente ácidos dos solutos orgânicos são iônicos e nenhum cálculo posterior é necessário. Contudo, águas de $\mathrm{pH}$ baixo do rio Negro anula a ionização dos ácidos orgânicos, e o grau de ionização precisa ser determinado. O grau de ionização de ácidos orgânicos foi computado, supondo-se que a constante média de equilíbrio $K=10^{4,5}$, e resolvendo a equação de equilíbrio para $\left[\mathrm{A}^{-}\right]$(ânions orgânicos) após substituindo o valor de $\left[\mathrm{H}^{+}\right]$determinado pelo $\mathrm{pH}$. 
TABELA 1 - Análise inorgânica das águas dos rios.

\begin{tabular}{lcccc} 
& Rio Negro & Rio Negro & Rio Branco & Rio Solimões \\
Constituintes & nos estreitos & acima do rio Brarico & acima do rio Negro & acima do rio Negro \\
\hline $\begin{array}{l}\text { PH } \\
\text { Condutividade específica } \\
\text { (em micromhos à } 25^{\circ} \mathrm{C} \text { ) }\end{array}$ & 4.9 & 4.2 & 6.6 & 7.2 \\
\hline
\end{tabular}

Miligramas por litro

\begin{tabular}{|c|c|c|c|c|}
\hline Silica $\left(\mathrm{SiO}_{2}\right)$ & 3.7 & 3.1 & 10.6 & 7.9 \\
\hline Calcio $(\mathrm{Ca})$ & 0.25 & 0.17 & 1.77 & 10.00 \\
\hline Magnesio $(\mathrm{Mg})$ & 0.11 & 0.06 & 0.99 & 1.48 \\
\hline Sodio (Na) & 0.41 & 0.32 & 1.94 & 2.50 \\
\hline Potassio (K) & 0.28 & 0.26 & 1.18 & 0.99 \\
\hline Ferro, $(\mathrm{Fe})$, total & 0.11 & 0.13 & 0.01 & 0.20 \\
\hline Alumínio (Al), total & 0.09 & 0.12 & 0.01 & 0.01 \\
\hline Bicarbonato $\left(\mathrm{HCO}_{3}\right)$ & 0.01 & 0 & 15.4 & 36.0 \\
\hline Sulfato $\left(\mathrm{SO}_{4}\right)$ & 0.18 & 0.19 & 0.26 & 3.82 \\
\hline Cloro (Cl) & 0.34 & 0.25 & 0.57 & 2.11 \\
\hline Nitrato $\left(\mathrm{NO}_{3}\right)$ & 0.17 & 0.04 & 0.26 & 0.99 \\
\hline
\end{tabular}

TABELA 2 - Análise de fracionamento do carbono orgânico dissolvido das águas dos rios.

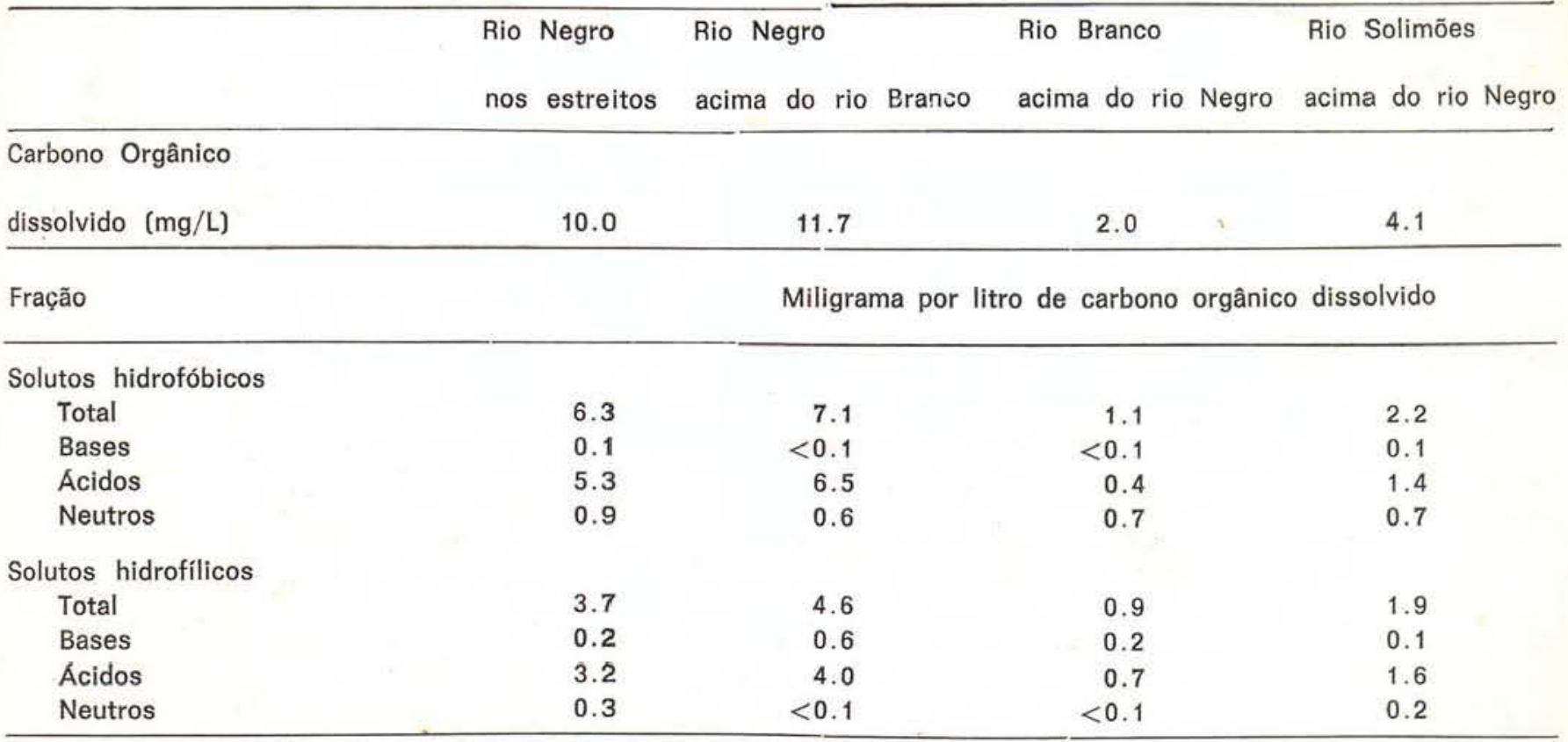

Ânions ácido orgânico nas amostras do rio Negro foram determinados multiplicando-se os miliequivalentes ânion orgânico total pelo grau de ionização. O equilíbrio ânion-cation dado na tabela 3 foi razoável para todas amostras, exceto o rio Negro acima do rio Branco, no qual os ânions são baixos, muito possivelmente por causa de um erro analítico não detectado.
A proporção de ânions orgânicos com ânions inorgânicos, na tabela 3 , claramente mostra a importância dos ácidos orgânicos no rio Negro. Os ânions orgânicos são 4 a 5 vezes mais abundantes que os ions inorgânicos no rio Negro; enquanto que, os ânions inorgânicơs são vinte vezes a concentração miliequivalente ânion orgânico no rio Branco e rio Solimões. Baseada nas concentrações de cátions totais, a 
TABELA 3 - Análise iônica para formas solúveis nas águas dos rios.

\begin{tabular}{lllll}
\hline Constituintes iônicos & Rio Negro & Rio Negro & Rio Branco & Rio Solimões \\
& nos estreitos acima do rio Branco acima do rio Negro acima do rio Negro
\end{tabular}

(Miliequivalentes por litro)

\begin{tabular}{lllll}
\hline Cations de metais inorgânicos & 0604 & 0517 & 2842 & 7610 \\
lon hidrogênio & 0126 & 0631 & 0003 & 0001 \\
Ânions inorgânicos & 0162 & 0116 & 2782 & 7542 \\
Ânions orgânicos & 0783 & 0452 & 0104 & 0385 \\
& & & 2845 & 7611 \\
Cátions total & 0730 & 1148 & 2922 & 7837 \\
Ânions total & 0945 & 0568 & & 05 \\
Ânions orgânicos & & & 05 \\
Ânions inorgânicos & 4.83 & 3.89 & & 05 \\
\hline
\end{tabular}

água do rio Branco tem três vezes, e o rio Solimões oito vezes a concentração iônica do rio Negro. Em virtude de os ânions orgânicos serem só parcialmente dissolvidos no $\mathrm{pH}$ do ric Negro, o input ênion orgânico real do rio Negro para dentro do rio Solimões e cerca de 1,5 vezes o valor ânion orgânico dado para o rio Negro nos estreitos, face à dissociação ácido-orgânica quando o $\mathrm{pH}$ se eleva até próximo da neutralidade durante a mistura das águas do rio Negro e rio Solimões.

RELAÇÕES DA CONDUTIVIDADE ESPECÍFICA E PH DURANTE A MISTURA DAS ÁGUAS DOS RIOS

Para determinar os efeitos do $\mathrm{pH}$ e condu. tividade específica sobre a química da água e o transporte de sedimento durante a mistura do rio Branco com o rio Negro, e do rio Negro com o rio Solimões, águas destes rios foram misturadas sob condições controladias no laboratório, e medidos o pH e a condutividade específica. Os resultados são apresentados nas figuras 2 e 3 .

A forma de curva de $\mathrm{pH}$ para o rio Branco misturado com o rio Negro é semelhante a uma curva de titulação de $\mathrm{pH}$ de um ácido orgânico fraco como o ácido acético. Existe um leve

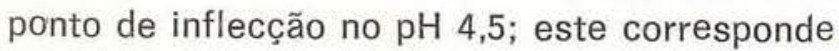
ao valor estimado de pK de 4,5 usado no cálculo dos miliequivalentes orgânicos. O rio Negro age como um ácido e o rio Branco como uma base. A curva de $\mathrm{pH}$ do rio Negro-rio Solimões é semelhante, exceto que o rio Negro amostrado nos estreitos é um ácido mais fraco e o rio Solimões é uma base mais forte.
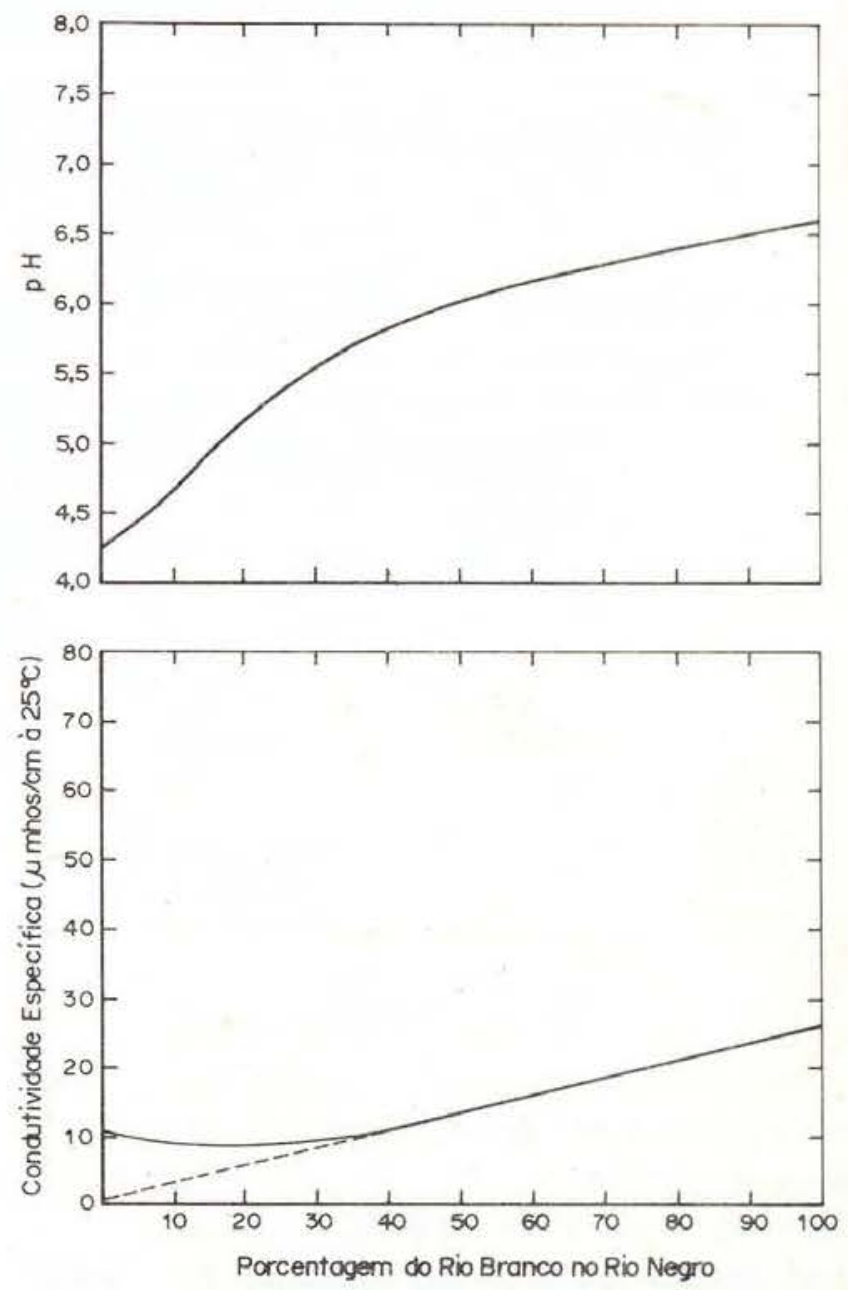

Fig. 2 - Curvas de condutividade específica e $\mathrm{pH}$ pro. duzidos pela mistura das águas do rio Branco com as águas do rio Negro. 

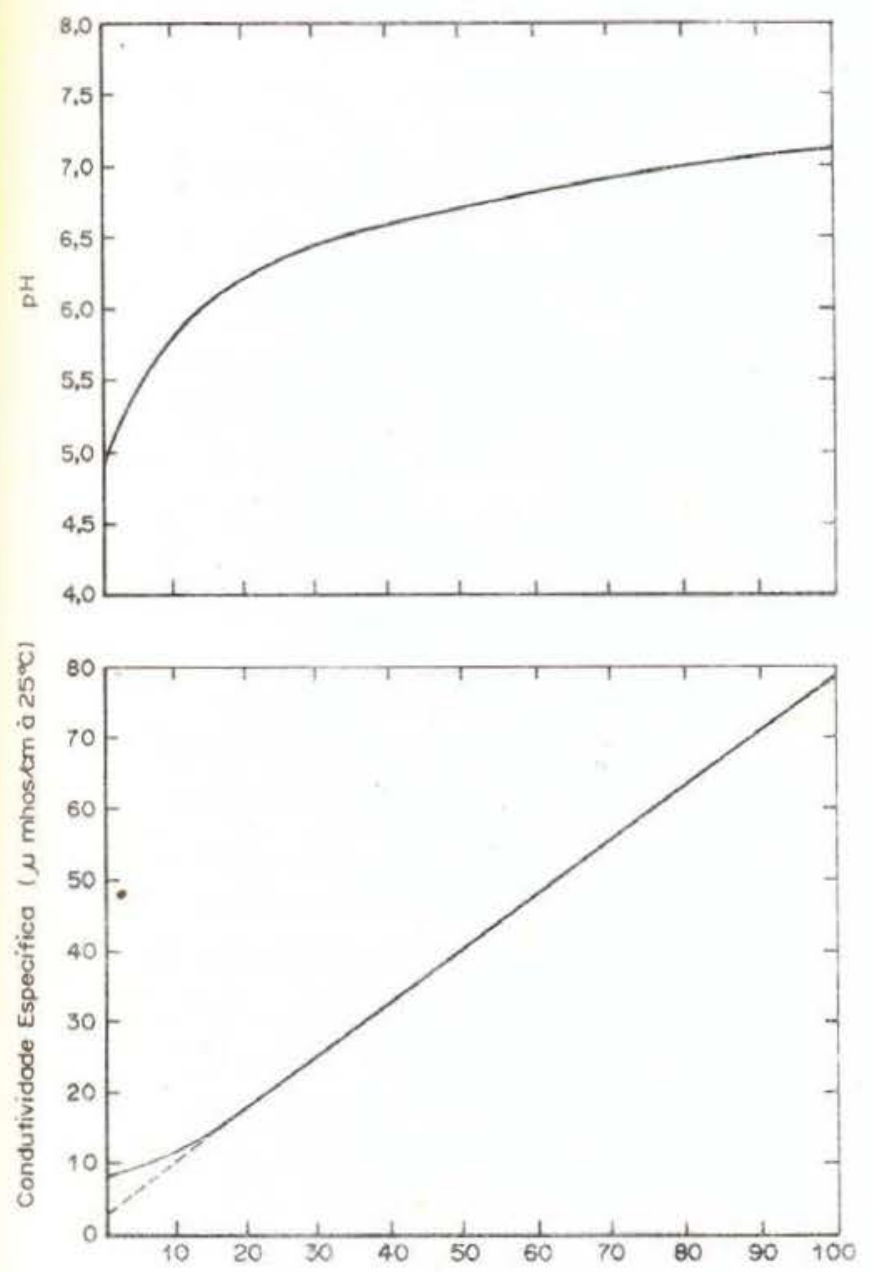

Porcertagem do Rio Solimōes no Rio Negro

Fig. 3-Curvas de condutividade específica e $\mathrm{pH}$ produzidos pela mistura das águas do rio Solimões com as águas do rio Negro.

Os gráficos de condutividade específica exibiram uma relação linear direta, à medida que a percentagem de água com concentração iônica maior aumentava, mas o gráfico é linear somente acima do $\mathrm{pH} 5,5$; os valores de condutividade específica são maiores que os previs tos do gráfico linear, uma vez que o ion hidro. gênio carrega uma quantidade de corrente elé. trica maior do que os ânions e cátions, tal como $\mathrm{Na}+$ e $\mathrm{Cl}^{-}$que determinam a porção linear do gráfico. Este efeito pH-condutividade nas águas pretas foi também observada por Sioli (1968), e Klinge \& Ohle (1964).

Supondo que o aumento no $\mathrm{pH}(4,2$ para $4,9)$ no rio Negro, do ponto de coleta acima do rio Branco para o ponto de coleta no estreito, foi devido à entrada de águas $\mathrm{com} \mathrm{pH}$ mais elevados do rio Branco, a curva de $\mathrm{pH}$ da figura 2 pode ser usada para estimar que $15 \%$ da água no rio Negro nos estreitos foi lançada no rio Branco no período da amostragem. Mais significativamente, o sedimento em suspensão no rio Branco em pH 6,6 experimentou uma queda de pH para 4,9 após a mistura com o rio Negro, esta completa. Por isso, a química da água do rio Negro foi só ligeiramente mudada pelo rio Branco no período da coleta, mas o pH e a concentração iônica do ambiente do sedimento em suspensão mudaram significativamente.

O rio Negro conta com cerca de $38 \%$ do fluxo e o rio Solimões conta com cerca de $62 \%$ do fluxo no local para onde estes rios convergem (Oltman, 1964), embora a percentagem do fluxo do rio Negro fosse determinada como variando entre 19 e $68 \%$ (Matsui et al., 1976). Para uma taxa de mistura de 38:62, o sedimento em suspensão no rio Solimões experimentaria uma queda no $\mathrm{pH}$ de 7,2 para 6,8 (Fig. 3) . e um decréscimo da condutividade de 78 para 48. Por isso, no encontro das águas do rio $\mathrm{Ne}$ gro e rio Solimões, a química da água do rio Solimões predomina no curso do rio Amazonas abaixo da convergência após a mistura com. pleta das águas.

Grande mudança na química da água (especialmente decréscimo do $\mathrm{pH}$ e acréscimo de ácido orgânico) na convergência dos rios $\mathrm{Ne}$ gro e Branco é mais possivelmente responsável pela floculação de sedimentos finos do rio Branco. Na convergência Negro-Solimões, a mudança na química da água é muito pequena para causar floculação do sedimento trazido pelo rio Solimões.

ANÁLISE DO TAMANHO DA PARTÍCULA DAS AMOSTRAS DE SEDIMENTO DO LEITO E ILHAS FLUVIAIS

As distribuições do tamanho da partícula das amostras de sedimento coletadas em vários pontos de amostragem por todo o arquipélago das Anavilhanas no rio Negro até à fonte de sedimento, o rio Branco, são fornecidas na tabela 4 .

Ao mover-se rio acima da região inferior da zona de deposição de sedimento até à fonte dos sedimentos, o percentual de areia aumenta; o percentual de silte diminui; e pouca mudança é vista no percentual de argila para as 
TABELA 4 - Análise do tamanho de partícula das amostras do sedimento do leito e ilhas fluviais.

\begin{tabular}{|c|c|c|c|c|}
\hline $\begin{array}{c}\text { Número na } \\
\text { Figura } 1\end{array}$ & Amostra & $\begin{array}{c}\text { Percentagem de areia } \\
(062 \mathrm{~mm})\end{array}$ & $\begin{array}{l}\text { Percentagem de silte } \\
\qquad(062-004 \mathrm{~mm})\end{array}$ & $\begin{array}{c}\text { Percentagem de argila } \\
\text { ( } 004 \mathrm{~mm})\end{array}$ \\
\hline 1 & Baixas Anavilhanas & 3.5 & 52.3 & 44.2 \\
\hline 2 & Sedimento do leito do rio Negro & 2.1 & 37.8 & 60.1 \\
\hline 3 & Médias Anavilhanas & 13.7 & 38.2 & 48.1 \\
\hline 4 & Rio Negro abaido do rio Branco & 21.8 & 32.9 & 45.3 \\
\hline 5 & Rio Branco & 23.9 & 28.7 & 47.4 \\
\hline
\end{tabular}

amostras de ilhas fluviais. Esta tendência de separação de sedimento não é invulgar para uma zona de deposição de sedimento em um rio; contudo, a baixa percentagem de areia e a alta percentagem de silte são julgadas ser características para ilhas do arquipélago das Anavilhanas. O limite inferior do rio Branco tem extensos bancos de areia, que indicam ativo transporte de partículas do tamanho de um grão de areia. As velocidades de corrente não são significativamente mais lentas no ric Negro da boca do ric Branco para abaixo, pelo arquipélago das Anavilhanas, mesmo o aparente desaparecimento de areia indica que ela não está sendo transportada até longe no rio Negro. Ilhas de bancos de areia do rio Branco têm sido substituídas por ilhas de banco de silte do rio Negro. Exame microscópico das frações de areia nas baixas Anavilhanas e no sedimento do leito do rio Negro não revelaram areia de quartzo; a maior parte da areia consistia de espículas de sílica de esponjiários, possivelmente das famílias Spongilla e Myenia (Easton, 1960), indicando uma origem biogênica para a areia.

A fração de argila não mostra variação significativa entre as amostras das ilhas fluviais, mas esta é maior na amostra de sedimento do leito que foi coletada adjacente à amostra das baixas Anavilhanas. A alta percentagem de argila no sedimento do leito, alta percentagem de silte nas ilhas fluviais e grau muito baixo de transporte de areia, são compatíveis com a hipótese da floculação de partícula porque areia agregada com silte e argila é provavelmente muito grande para transporte de sedimento; partículas de silte agregadas com outra partícula de silte e com argila formam partículas do tamanho de areia que são os componentes principais das ilhas do arquipélago das Anavilhanas, e partículas de argila floculadas mais provavelmente são sedimentadas como o silte. Observação direta de partículas floculadas em suspensão no rio Negro, logo abaixo da boca do rio Branco, e as concentrações de sedimento em suspensão muito baixas do baixo rio Negro, abaixo do arquipélago das AnaviIhanas, fornece apoio adicional para a hipótese da floculação de partícula.

\section{COMPLEXAÇ̃̃O DA ARGILA ORGÂNICA NO RIO NEGRO}

Polieletrólitos orgânico sintético são freqüentemente usados para flocular argila em suspensão em sistemas de tratamento de água. Substâncias húmicas dissolvidas no rio Negro poderiam possivelmente agir como polieletrólitos aniônicos naturais, que poderiam intensificar a floculação da argila na água preta do rio Negro.

Para determinar se os solutos húmicos estavam associados com a argila no sedimento, os solutos húmicos na água do rio Negro no estreito foram caracterizados por espectrocóspio infravermelho e análise de elementos; estas análises foram comparadas com os espectros infravermelhos e composição elementar do extrato de matéria orgânica da amostra do sedimento do leito do rio Negro. A análise elementar é dada na tabela 5 , e espectros iniravermelhos estão apresentados no figura 4. 
As composições elementares da matéria orgânica da água e sedimento do rio Negro são quase idênticas. Nitrogênio é mais alto no extrato de sedimento, dados os materiais húmicos ligados com argila caolinita que predomi. nam no sedimento, através de grupos funcionais amino-nitrogênio contidos nas moléculas húmicas (Wershav \& Pinckney, 1979). O valor de $3,1 \%$ de carbono orgânico é alto, como a maioria dos solos circundantes contém menos que $2 \%$ de carbono orgânico (Williams et al., 1972).
Nos espectros infravermelho da figura 4 , argila caolinita mostra várias faixas de absor. çäo pronunciadas em $3700 \mathrm{~cm}^{-1}, 3625 \mathrm{~cm}^{-1}$. $1095 \mathrm{~cm}^{-1}, 1035 \mathrm{~cm}^{-1}, 1010^{-1}, 915 \mathrm{~cm}^{-1}, \mathrm{e}$ $540^{-1}$, para a amostra do sedimento do leito Esta caolinita é mais provavelmente complexada com o material húmico, porque ela não pode ser separada do extrato pelos processos de separação de extração, filtração e troca iônica. Espectros infravermelhos da amostra d'água não mostram nenhuma argila caolinita, mas faixas de absorção em $1080 \mathrm{~cm}^{-1}$ e $800 \mathrm{~cm}^{-1}$

TABELA 5 - Composiçăo orgânica elementar da água e sedimento do leito do rio Negro.

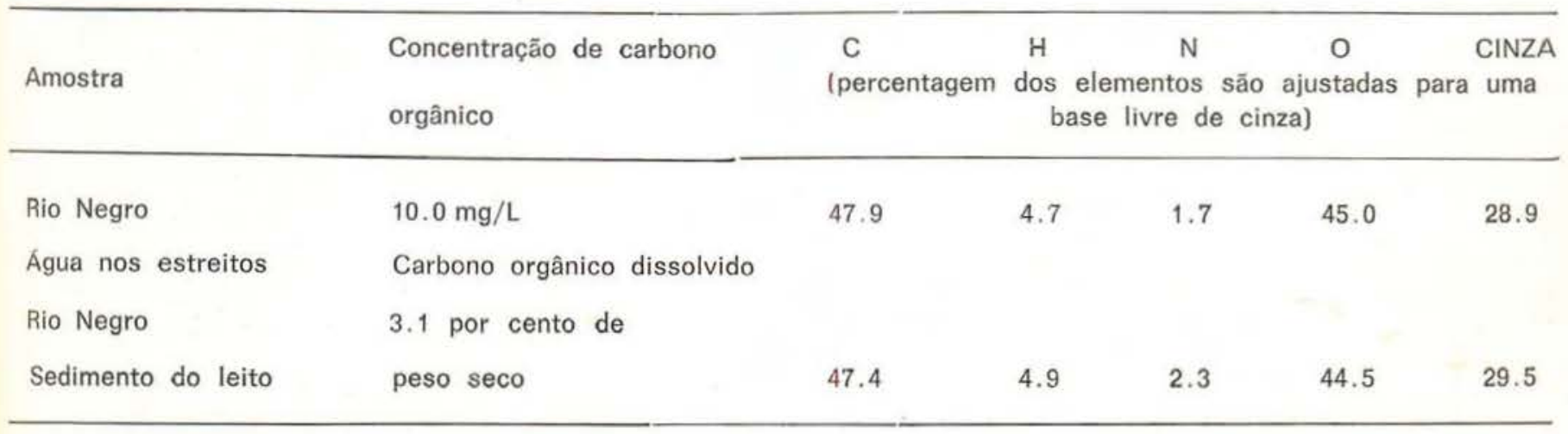

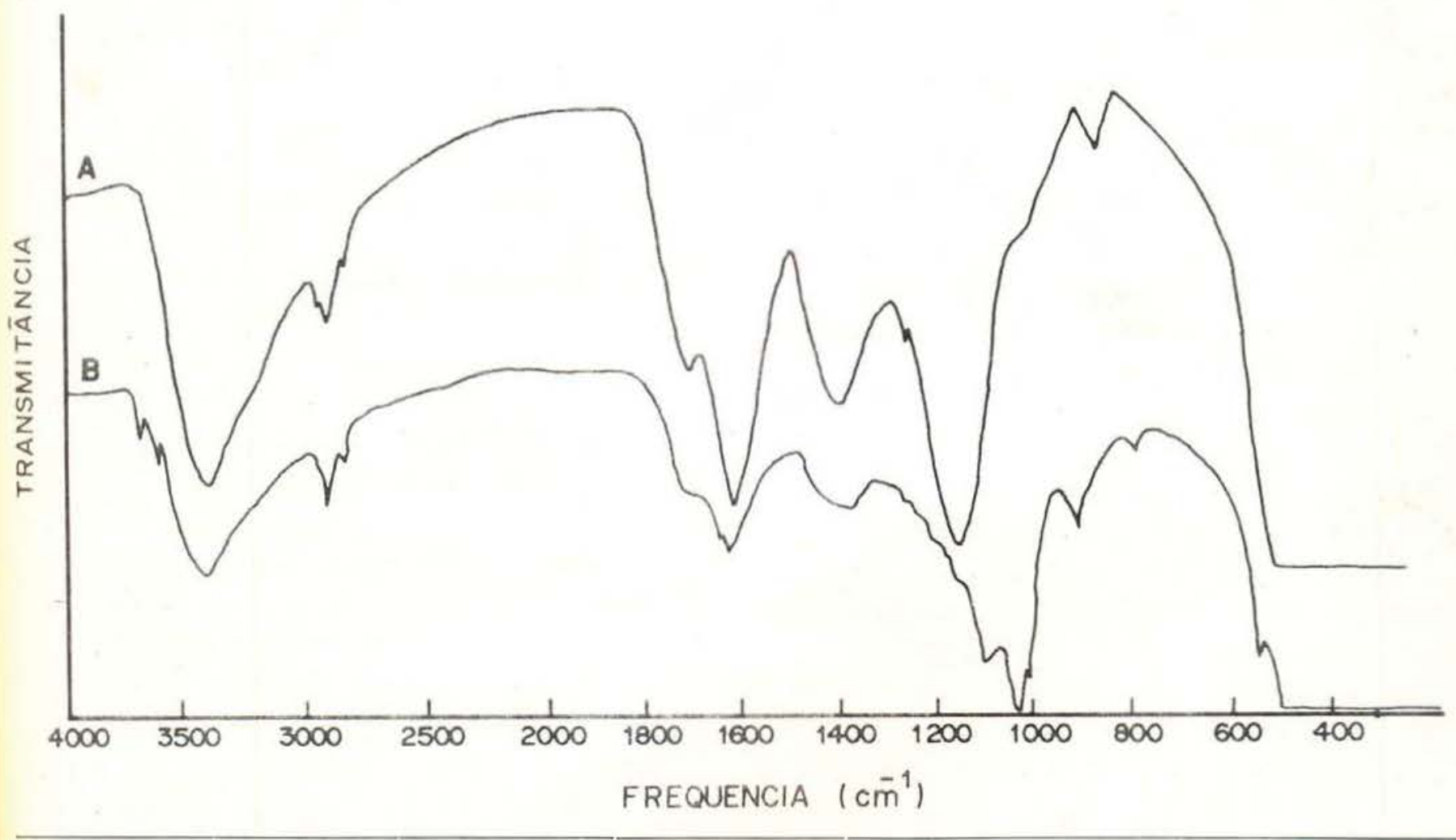

Fig. 4 - Espectros infravermelhos de extratos de matéria orgânica das águas e sedimento do leito do rio Negro. 
indicam sílica, que foi também detectada na análise da água dada na tabela 1. Porções or. gânicas dos dois espectros infravermelhos, que podem ser visualizados pelo desprezo das faixas de absorção da caolinita e sílica, são virtualmente idênticas.

Tanto os dados elementares como os espectros infravermelhos indicam que a matéria orgânica na água e sedimento do rio Negro têm uma origem comum. Porque a matéria orgânica não é provavelmente produzida dentro do sedimento do leito do rio Negro, dada a sua baixa profundidade biológica e porque o sedimento do leito contém mais carbono orgânico que o solo circundante, a única explicação lógica é que a argila em suspensão é complexada com matéria orgânica dissolvida, e este complexo argila-matéria orgânıca é um componente principal do sedimento do leito.

\section{VARIAÇÕES ESTACIONAIS QUE ATINGEIM O} TRANSPORTE DE SEDIMENTO NO RIO NEGRO

Os dados apresentados neste trabalho foram coletados durante a estação chuvosa quando o rio Negro estava subindo. Dados sazonais de precipitação para a bacia do rio Amazonás foram recentemente registrados por Salati et al. (1978). O pico da estação chuvosa ocorre durante maio-julho tanto para a bacia do alto rio Negro como para a bacia do rio Branco, mas c alto rio Negro nunca tem uma estação seca enquanto que a bacia do rio Branco tem uma estação seca de novembro até fevereiro. A maior descarga para o rio Branco ocorre entre julho e outubro, e a mais alta percentagem de contribuição da descarga do rio Branco para o rio Negro também muito parcialmente ocorre durante julho até outubro, Apesar da alta descarga para o alto rio Negro e rio Branco duran te julho até outubro, o trecho do baixo rio $\mathrm{Ne}$ gro está caindo durante este período face ao baixo estágio do rio Solimões. Conseqüentemente, as maiores velocidades de corrente no baixo rio Negro são observadas em julho até outubro durante o estágio de baixa. Alta descarga e altas velocidades de correntes durante o período de baixa, muito provavelmente são os principais fatores que aumentam o transpor. te de sedimento e causa erosão e deposiçăc das ilhas do arquipélago das Anavilhanas. Contudo, mudanças sazonais na química da água do rio Negro podem também ser significativas .

Dados sazonais de $\mathrm{pH}$ e condutividade específica coletados pelo INPA na ilha Tauatu, na parte superior do arquipélago das Anavilhanas. ilha das Onças, logo acima do rio Camanau, e na boca do rio Branco, são dados na tabela 6 . Os dados na tabela 6 mostram que os valores de $\mathrm{pH}$ e condutividade específica são menores para os locais no rio Negro do que no rio Branco, exceto para a amostra de setembro, na qual todos os três locais deram aproximadamente os mesmos valores. Setembro corresponde ao período de fluxo alto no rio Branco; assim, a química da água do lado nordeste do baixo rio Negro foi dominada pela química da água do rio Branco durante setembro de 1974. Na amostra de dezembro de 1974 , os valores do $\mathrm{pH}$ para as amostras do rio Negro são ainda elevados, mas os valores da condutividade específica cairam muito abaixo do rio Branco. A elevação sazonal nos valores do pH no baixo rio Negro, nas vizinhanças do arquipélago das Anavilhanas, pode significativamente aumentar o trans. porte de sedimento em suspensão e sedimento do leito pelas seguintes razões :

1. O mineral dominante no sedimento em suspensão e do leito no rio Negro é a caolinita (Gibbs, 1967), que tem um ponto de carga zero no $\mathrm{pH} 4,6\left(\mathrm{pH}_{2} \mathrm{PC}=4,6\right)$ (Stumm \& Morgan, 1970). A caolinita é conhecida em flocular suspensões ácidas onde sua carga da superfície é próxima de zero (Schofield \& Sampson, 1954) e desflocular quando o $\mathrm{pH}$ é elevado. Os dados na tabela 6 mostram que normalmente o pH do baixo rio Negro é baixo o suficiente de maneira que a caolinita permaneceria floculada, mas em setembro, a elevação do $\mathrm{pH}$ pode deflocular o sedimento do leito, constituído de caolinita, ocorrendo o transporte de sedimento;

2. Se parte da argila caolinita no sedimento do leito está complexada com substâncias húmicas, a pH2PC diminuiria para $\mathrm{pH} 3,4-3,8$ (Van Ray \& Peech, 1972), o que poderia ajudar na desfloculação do sedimento do leito durante a elevação sazonal do $\mathrm{pH}_{\text {; }}$ 
TABELA 6 - Variações sazonais do $\mathrm{pH}$ e condutividade específica $\left(\mu \mathrm{S}_{20}\right)$ no baixo rio Negro.

\begin{tabular}{|c|c|c|c|c|c|c|}
\hline \multirow{2}{*}{ Data } & \multirow{2}{*}{\multicolumn{2}{|c|}{ Rio Branuco }} & \multicolumn{2}{|c|}{$\begin{array}{l}\text { Rio Negro na } \\
\text { Itha das Onças }\end{array}$} & \multirow{2}{*}{\multicolumn{2}{|c|}{$\begin{array}{l}\text { Rio Negro na } \\
\text { Ilha Tauatu }\end{array}$}} \\
\hline & & & pH & $\mu \mathrm{S}_{20}$ & & \\
\hline 1974 (maio) & 6.2 & 22.4 & 4.8 & 11.7 & 4.7 & 12.1 \\
\hline 1974 (setembro) & 5.2 & 14.4 & 5.1 & 12 & 5.2 & 12.1 \\
\hline 1974 (dezembro) & 6.0 & 17.4 & 5.2 & 9.0 & 5.2 & 8.9 \\
\hline 1975 (fevereiro & 6.0 & 19.0 & 4.6 & 11.4 & 4.6 & 11.4 \\
\hline 1975 (abril) & 5.9 & 18.9 & 4.7 & 9.5 & 4.7 & 9.9 \\
\hline
\end{tabular}

3. Durante a elevação sazonal do $\mathrm{pH}$ devida ao influxo da água do rio Branco, a concentração de solutos húmicos que promove a floculação e sedimentação da argila pode também diminuir porque a água do rio Branco é pobre em solutos húmicos.

Evidência experimental direta sobre a floculação e desfloculação do sedimento do rio Negro, como uma função do $\mathrm{pH}$, é necessária para confirmar as hipóteses e observações de campo deste trabalho. Estas hipóteses são apresentadas para enfatizar a potencial importância da química da água no rio Negro, como sendo relacionada com o transporte de sedimento.

HIPÓTESES DE TRANSPORTE DE SEDIMENTO NO BAIXO RIO NEGRO

A maior parte do influxo de sedimento para - baixo rio Negro se origina do rio Branco. Durante o período (novembro a dezembro) de baixo fluxo do rio Branco, supomos que o input de sedimento em suspensão pelo rio Branco é floculado no rio Negro em uma distância relativamente curta abaixo da boca do rio Branco, face a uma diminuição do $\mathrm{pH}$ da água para perto do $\mathrm{PH}_{2} \mathrm{PC}$ do sedimento, e dada a formação de complexos caolinita-húmicos. O sedimento floculado tem-se agrupado em tamanhos de partícula muito grandes para per. manecer em suspensão, de modo que eles se depositam. Contudo, quando ocorre alto fluxo no rio Branco (julho a outubro), o pH do lado nordeste do baixo rio Negro aumenta; contendo soluto húmico, diminui; e como um resulta- do, desfloculação e ressuspensão do sedimento do leito pode ocorrer nas altas Anavilhanas. Correntes altas durante o estágio de baixa do baixo rio Negro durante este período elevaria grandemente a taxa de transporte de sedimento. As águas dos rios Branco e Negro podem não misturar-se até atingir a parte inferior do arquipélago das Anavilhanas, e o sedimento floculado responsável pelo crescimento de ilha pcde também não se formar até a mistura das águas no baixo arquipéiago das Anavilhanas. 0 transporte de sedimento em suspensão é um fenômeno sazonal que é julgado ser principal. mente dependente das taxas de input de sedimento do rio Branco e das velocidades da corrente no baixo rio Negro, e, secundariamente, dependente das mudanças na química da água ( $\mathrm{pH}$ e conteúdo de soluto húmico) que atingem a floculação e desfloculação do sedimento em suspensão e do sedimento do leito.

A forma caracteristicamente alongada das ilhas fluviais do arquipélago das Anavilhanas pode ser formada principalmente por uma seqüência erosiva do transporte de sedimento em lugar de uma seqüência de depósito. Durante a água alta no baixo rio Negro, o pH é baixo; as ilhas estão sob a água; e sedimento floculado é uniformemente depositado de maneira que nenhuma evidência visível de estratificação é aparente. Quando o trecho do baixo rio Negro está secando, as velocidades de corrente aumentam, o pH se eleva face ao alto estágio do rio Branco; o sedimento no leito nos canais entre as ilhas fluviais é parcialmente desfloculado, e a erosão dos canais seletivamente transporta sedimento do leito do rio em 
vez das ilhas. Transporte de sedimento das ilhas só ocorre quando os canais erodem os bancos das ilhas, e os bancos desmoronam dentro dos canais.

Esta hipótese de transporte de sedimento no baixo riơ Negro só fornece uma descrição qualitativa de fatores geoquímicos que afetam os processos de sedimentação. Dados adicionais de geologia, hidrologia e geoquímica são necessários para provar ou não a hipótese de transporte de sedimento apresentada neste trabalho.

Experimentos específicos projetados para testar a hipótese de floculação de sedimento incluem: (1) programa de coleta mensal de dados de campo para determinar as concentra. ções de sedimento em suspensão, distribuição de tamanho de partícula, dados de descarga e velocidades da corrente, $\mathrm{pH}$ e condutividade específica e conteúdo de carbono orgânico dissolvido nas águas do rio Branco até o baixo rio Negro, através de todo o arquipelago das Anavilhanas; (2) observações de campo e medidas de erosão de banco e taxas de deposição de sedimento por todo o arquipélago das Anavilhanas, de ano para ano, e de estação para estação; (3) um levantamento para determinar tamanho de partícula de sedimentos coletados do leito do baixo rio Negro e rio Branco; e (4) conduzir experimentos de laboratório para determinar se as suspensões do rio Branco são: (a) floculados na água do rio Negro e (b) des. floculados pela adição de água de $\mathrm{pH}$ mais elevado.

\section{AgradeCIMENTOS}

Este trabalho foi financiado pelo Department of Scientific Affairs of the Organization of American States. O U.S. Geological Survey forneceu apoio de laboratório e salário para o primeiro autor, e o Instituto Nacional de Pesquisas da Amazônia (INPA) forneceu o barco, tripulação e facilidades de pesquisa que tornaram este trabalho possível.

Desejamos particularmente agradecer ao Dr. Warwick E. Kerr, então Diretor do INPA, e à Dra. Ilse Walker, coordenadora da OEA no INPA, pelo apoio administrativo e técnico. Reconhecimento é também expresso para a tri. pulação do "Pyatã", Adamor, João Batista e Chiquinho, por sua companhia e assıstência durante a excursão no rio, e para Cora Lee nheer por seu serviço como tradutora.

\section{SUMMARY}

The narrow, elongated morphology of the river islands called the Anavilhanas Archipelago, found in the lower Rio Negro, suggests sedimentation processes which differ from other Amazon tributaries, which have lens-shaped river islands. A study of the geochemistry of the water and sediment of the Rio Negro, Rio Branco, and Rio Solimoes suggested that kaolinitic suspended sediments from the Rio Branco were being flocculated by the acid black water of the Rio Negro. due to $\mathrm{pH}$ reduction to the zero point of charge of the sediment, and because of the formation of humic-kaolin clay complexes. No sediment flocculation was observed where the Rio Negro combined with the Rio Solimōes; as the $\mathrm{pH}$ change at this convergence was slight. Sedimentation of flocculates in the lower Rio Negro produces unstratified deposits, which are manifested by elongated islands consisting mainly of silt and clay, and bed sediment of very-high clay content.

\section{BIBLIOGRAFIA}

EASTON, W.H.

1960 - Invertebrate Paleontology. New York, Harper and Row, p. 99-122.

GIBBS, R.J.

1967 - The geochemistry of the Amazon River System. Part 1. The factors that control the salinity and the composition and concentration of the suspended solids. Geological Society of American Bulletin, 78: 12031232.

GUY, H.P.

1969 - Laboratory theory and methods for sediment analysis U.S. Geological Survey Techniques Water-Resources Investigations, book 5, chapter $\mathrm{Cl}, 58 \mathrm{p}$.

KLINGE, H. \& OHLE, W.

1964 - Chemical properties in the Amazonian area in relation to soil conditions. Verh. Internat. Verein. Limnol., 15: 1069-1076.

LEENHEER, J.A. \& HUFFMAN JR., E.W.D.

1979 - Analytical method for dissolved-organic carbon fractionation. U.S. Geological Survey Water-Resources Investigations 79-4, $16 \mathrm{p}$.

MALCOLM, R.L. \& LeENHEER, J.A.

1973 - The usefulness of organic carbon parameters in water quality investigations. Proceedings of the 19th Annual Technical Meeting, Institute of Environmental Sciences, Anaheimn California, April 1973, p. 336-340. 
MAlCOLM, R.L.; LeENHEeR, J.A.; MCKINLEY, F.W. \& ECCLES, L.A.

1973 - Supplement II - Organic carbon. IN: Methods for analysis of organic substances in water (D.F. Goerlitz and E. Brown, eds) U.S. Geological Survey Techniques WaterResources Investigations, book 5, chapter A3, 34p.

Matsui, E.; Salati, E.; Friedman, I. \& Brinkman, W.L.F.

1976 - Isotope hydrology in the Amazonia 2. Relative discharges of the Negro and Solimoes rives through 180 concentrations. Water Resources Res., 12: 781-785.

MEAdE, R.H.; NoRdin JR., C.F.; CURTIS, W.F.; MAHONEY, H.A. \& DELANEY, B.M.

1979 - Suspended-sediment and velocity data, Amazon river and its tributaries, June-July 1976 and May-June 1977 U.S. Geological Survey Open-File Report 79-515, 42p.

Oltman, R.E.; Sternberg, H.O.R.; AMEs, F.C. \&

DAvis JR., L.C.

1964 - Amazon River investigations reconnaissance measurements of July 1963. U.S. Geological Survey Circular 486.

Salati, E.; Marques, J. \& Molian, L.C.B.

1978 - Origem e distribuição das chuvas na Amazônia: Interciência, 3: 200-206.

SCHOFIELD, R.K. \& SAMSON, H.R.

1954 - Flocculation of kaolinite due to the attraction of oppositely charged crystal faces. Faraday.
Society (London) Discussions 18, p. 135145.

SioLI, $\mathrm{H}$.

1966 - Studies in Amazonian waters (Conferência). Atas do Simpósio sobre a Biota Amazônia: Limnologia, 3: 117-126.

1968 - Hydrochemistry and geology in the Brazilian Amazon region: Amazoniana, 1: 267-277.

Stumm, W. \& MORgan, J.J.

1970 - Aquatic Chemistry New York, Wiley - Intersciencia, p. 478.

VAN RAY, B. \& PEECH, M.

1972 - Electrochemical properties of some oxisols and alfisols of the tropics. Soil Science Society of America Proceedings, 36: 587-593.

WeRSHAW, R.L. \& PINCKNEY, D.J.

1979 - Isolation characterization of clay-humic complexes. Presented at 1979 National Meeting of the American Chemical Society, Sym. posium on Processes Involving Contaminants and Sediments, Honolulu, Hawaii, April 1979. In preparation.

WrLlams, W.A.; LOOMIs, R.S. \& ALvin, P. DE T.

1972 - Environment of evergreen rain forests on the lower Rio Negro, Brazil: Tropical Ecology, 13: 65-79.

(Aceito para publicaçăo em 11/03/80) 